\title{
Preface to the special issue on plasma facing materials for fusion energy
}

\author{
Guang-Nan Luo ${ }^{1} \cdot$ Guanghong $\mathrm{Lu}^{2} \cdot$ Xiang $\mathrm{Liu}^{3}$
}

Published online: 5 August 2019

(C) The Nonferrous Metals Society of China 2019

International thermonuclear experimental reactor (ITER), the largest tokamak device so far, will operate with a full-tungsten divertor to handle the steady heat fluxes of $10 \mathrm{MW} \mathrm{m}^{-2}$, the slow transients of $20 \mathrm{MW} \mathrm{m}^{-2}(\sim 10 \mathrm{~s})$, as well as the transient heat fluxes up to $\sim \mathrm{GM} \mathrm{m}^{-2}(<1 \mathrm{~ms})$. Currently, tungsten (W) is also foreseen as the most suitable plasma-facing material (PFM) for the first wall in demonstration (DEMO) and future fusion reactors, as well as the divertor. The wall material in future fusion reactors must fulfill the requirements of sufficient lifetime, negligible or small long-term retention of tritium $(\mathrm{T})$ fuel and an acceptable neutron activation level in long-term operation, which are favorable for $\mathrm{W}$ walls. However, the compatibility with a good plasma performance is a main concern for the high$\mathrm{Z}$ (atomic number) $\mathrm{W}$ material because of the high central radiation losses by the penetrated $\mathrm{W}$ atoms from wall erosion. Moreover, the high fluxes/fluences of particle species like deuterium (D), T, He, etc., and elevated surface temperatures, can change the surface morphology (formation of blistering, nanobubble, and fuzz), modify the mechanical and thermal properties at the surface/near-surface region of the W-PFM, and even cause damage (cracking, melting) with edge-localized mode (ELM)-induced (or disruptioninduced) thermal shocking. These will influence the powerhandling capabilities of the plasma-facing components (PFCs), even causing PFC failure for the normal plasma operation.

This special topic focuses on tungsten and its alloy/composite applied in magnetic confinement fusion as the PFMs, comprising six contributions with three review papers and

Guang-Nan Luo

gnluo@ipp.ac.cn

1 Institute of Plasma Physics, Chinese Academy of Sciences, Hefei 230031, China

2 School of Physics, Beihang University, Beijing 100191, China

3 Southwestern Institute of Physics, China National Nuclear Corporation, Chengdu 610041, China three research articles. One contribution summarizes the recent advances in understanding plasma-tungsten interactions, e.g., $\mathrm{W}$ erosion and melting in the tokamak device, Experimental Advanced Superconducting Tokamak (EAST, China). Pure $\mathrm{W}$ and $\mathrm{W}$ alloys, including $\mathrm{W}-\mathrm{V}, \mathrm{W}-\mathrm{Y}_{2} \mathrm{O}_{3}$, $\mathrm{W}-\mathrm{ZrC}, \mathrm{W}-\mathrm{K}, \mathrm{WCrY}$ and $\mathrm{W}-\mathrm{La}_{2} \mathrm{O}_{3}$, were examined and compared in terms of plasma-induced defects, generation and propagation of cracks, erosion, melting, and oxidation performances by some laboratory simulators, i.e., the linear plasma devices Plasma-Surface Interactions (PSI-2, Germany) and Simulator for Tokamak Edge Plasma (STEP, China), and the neutral beam heat load device Garching Large Divertor Sample test facility (GLADIS, Germany). $\mathrm{K}$-doped $\mathrm{W}$ was systematically reviewed in the respects of material preparation, mechanical properties, thermal shock resistance, and irradiation damages. The diamond filmcoated $\mathrm{W}$ alloys by a chemical vapor deposition (CVD) method were also described and characterized.

We hope that this special topic could provide a comprehensive insight into the status and prospective of $\mathrm{W}$ applications in fusion devices and inspire innovative ideas for the researchers and scientists in this field to resolve the remaining issues. Meanwhile, we would like to take this visible opportunity to express our sincere greetings to all the authors, reviewers, editors, and publishing staff for their great efforts and invaluable contributions for the publication of this special topic.

\section{Prof. Guang-Nan Luo \\ Prof. Guanghong Lu \\ Prof. Xiang Liu \\ May 16, 2019}

Publisher's Note Springer Nature remains neutral with regard to jurisdictional claims in published maps and institutional affiliations. 